Vicky Goh

Bal Sanghera

\section{Reply to letter to the editor: Assessment of the spatial pattern of colorectal tumour perfusion estimated at perfusion CT using two-dimensional fractal analysis}

Received: 12 May 2009

Accepted: 20 May 2009

Published online: 17 July 2009

(C) European Society of Radiology 2009

This reply refers to the Letter to the Editor available at doi:10.1007/s00330-0091487-2.

\section{Goh $(\bowtie) \cdot$ B. Sanghera}

Paul Strickland Scanner Centre,

Mount Vernon Hospital,

Rickmansworth Road,

Northwood, Middlesex, HA6 2RN, UK

e-mail: Vicky.goh@stricklandscanner.

org.uk

Tel.: +44-1923-844751

Fax: +44-1923-844600

\section{Response to 'The euclidean meaning of fractal abundance in perfusion imaging'}

Dear Editor,

We welcome the interest that Peng and Ko have shown in our paper [1] which aimed to assess if perfusion measured at $\mathrm{CT}$ demonstrated fractal properties. The measures we evaluated - fractal dimension (FD), fractal abundance (FA) and lacunarityhave been implemented previously in biological studies and are by no means new [2-5]. For example, studies of plant root systems have employed FD, FA and lacunarity [5]. Fractal abundance has been described as a measure of the volume of space explored by fractal analysis. With 2D analysis we agree that fractal abundance should demonstrate a correlation with the pixel number. Indeed our data show that FA correlates with the natural logarithm of the pixel number $\left(r^{2}=0.98\right)$ and also with tissue area $\left(r^{2}=0.87\right)$. However it is well recognized that correlation merely demonstrates the presence of a relationship between the two parameters and does not reflect an interchangeability.

\title{
References
}

1. Goh V, Sanghera B, Wellsted D, Sundin J, Halligan S (2009) Assessment of the spatial pattern of colorectal tumour perfusion estimated at perfusion CT using two dimensional fractal analysis. Eur Radiol. doi:10.1007/ s00330-009-1304-y

2. Baish JW, Jain RK (2000) Fractals and cancer. Cancer Res 60:3683-3688
3. Smith TG Jr, Lange GD, Marks WB (1996) Fractal methods and results in cellular morphology-dimensions, lacunarity and multifractals. J Neurosci Methods 69:123-136

4. Plotnick RE, Gardner RH, Hargrove WW et al (1996) Lacunarity analysis: a general technique for the analysis of spatial patterns. Phys Rev E Stat Phys Plasma Fluids Relat Interdiscip Topics 53:5461-5468
5. Walk TC, Van Erp E, Lynch JP (2004) Modelling applicability of fractal analysis to efficiency of soil exploration by roots. Ann Bot (Lond) 94:119-128 